\title{
BMJ Open Surgery during holiday periods and prognosis in oesophageal cancer: a population-based nationwide Swedish cohort study
}

\author{
Sheraz R Markar, ${ }^{1,2}$ Karl Wahlin, ${ }^{1}$ Fredrik Mattsson, ${ }^{1}$ Pernilla Lagergren, ${ }^{1}$ \\ Jesper Lagergren ${ }^{1,3}$
}

To cite: Markar SR, Wahlin K, Mattsson F, et al. Surgery during holiday periods and prognosis in oesophageal cancer: a population-based nationwide Swedish cohort study. BMJ Open 2016;6: e013069. doi:10.1136/ bmjopen-2016-013069

- Prepublication history for this paper is available online. To view these files please visit the journal online (http://dx.doi.org/10.1136/ bmjopen-2016-013069).

Received 21 June 2016 Revised 28 July 2016 Accepted 3 August 2016

CrossMark

\footnotetext{
${ }^{1}$ Department of Molecular medicine and Surgery, Karolinska Institutet, Karolinska University Hospital, Stockholm, Sweden ${ }^{2}$ Department of Surgery \& Cancer, Imperial College London, London, UK ${ }^{3}$ Division of Cancer Studies, King's College London, and Guy's and St Thomas' NHS Foundation Trust, London, UK
}

Correspondence to Dr Sheraz R Markar; s.markar@imperial.ac.uk

\section{ABSTRACT}

Objective: Previous studies indicate an increased short-term and long-term mortality from major cancer surgery performed towards the end of the working week or during the weekend. We hypothesised that the prognosis after major cancer surgery is also negatively influenced by surgery conducted during holiday periods.

Setting: Population-based nationwide Swedish cohort study.

Participants: Patients undergoing oesophagectomy for oesophageal cancer between 1987 and 2010. Among 1820 included patients, 206 (11.3\%) and 373 $(20.5 \%)$ patients were operated on during narrow and wide holiday periods, respectively.

Interventions: Narrow (7 weeks) and wide (14 weeks) Swedish holiday periods.

Primary and secondary outcome measures: 90day all-cause, 5-year all-cause and 5-year diseasespecific mortality.

Results: Narrow holiday period did not increase allcause 90 -day ( $\mathrm{HR}=0.84,95 \% \mathrm{Cl} 0.53$ to 1.33 ), allcause 5-year ( $\mathrm{HR}=1.01,95 \% \mathrm{Cl} 0.85$ to 1.21$)$ or disease-specific 5-year mortality $(\mathrm{HR}=1.04,95 \% \mathrm{Cl}$ 0.87 to 1.26$)$. Similarly, wide holiday period did not increase the risk of 90 -day $(\mathrm{HR}=0.79,95 \% \mathrm{Cl} 0.55$ to 1.13), all-cause 5 -year (HR=0.96, 95\% Cl 0.84 to 1.1) or disease-specific 5 -year mortality $(\mathrm{HR}=1.03,95 \% \mathrm{Cl}$ 0.89 to 1.19).

Conclusions: No measurable effects of holiday periods on short-term or longer term mortality following surgery for oesophageal cancer were observed in this population-based study, indicating that an adequate surgical experience was maintained during holiday periods.

\section{INTRODUCTION}

Large studies from the UK and US of various elective surgical procedures have shown increased 30-day mortality if the procedures were carried out on Friday or a weekend. ${ }^{12}$ These results may be attributable to lower

\section{Strengths and limitations of this study}

- The population-based design with virtually complete inclusion of all eligible patients in Sweden.

- The large sample size, complete follow-up of all patients and the adjustment for all relevant confounding factors are other advantages.

- The Swedish system with personal identity numbers of all residents and a nationwide population registry for dates and causes of death enabled complete assessment of mortality, without loss to follow-up.

Retrospective observational in design.

staffing density and experience during weekends, and have led to a call for a 7-day working week in the UK healthcare. Other studies have suggested that short-term and long-term mortality from major cancer surgery is influenced by both the hospital and surgeon volume, ${ }^{3-6}$ and the resources available to the centre to rescue the patient following a major complication. ${ }^{7}$ In a recent study, we found an intriguing increased longterm mortality with each later weekday of oesophageal cancer surgery during the weekdays Monday to Friday, particularly for earlier tumour stages. 8 In the present study, we hypothesised that surgical timing with respect to calendar period may also influence the prognosis following major cancer surgery. During holiday periods the experience and density of the surgeons and staff may be lower, which may contribute to worse outcomes. Oesophagectomy for cancer represents the ideal procedure to test this hypothesis, as it is a high-risk elective surgical procedure with a significant rate of measureable short-term and long-term mortality and has a stronger association with the experience of the hospital and surgeon than most other procedures. ${ }^{4}$ Sweden was considered 
an ideal country for this study because of its distinct holiday periods. We tested the new hypothesis that major cancer surgery conducted during holiday periods is followed by worse prognosis in a nationwide Swedish study of oesophageal cancer surgery.

\section{METHODS}

\section{Study design}

The design of this population-based cohort study has been described in detail elsewhere. ${ }^{9}$ In brief, this Swedish nationwide cohort study included $98 \%$ of all patients with oesophageal cancer treated with curative intended surgery between 1987 and 2010 with follow-up until November 2014. From the Swedish Cancer Registry, patients with a diagnosis of oesophageal cancer (150.0, 150.8 or 150.9) were identified according to the seventh edition of the International Classification of Diseases (ICD7). This Cancer Registry has 98\% nationwide coverage of oesophageal cancer. ${ }^{10}{ }^{11}$ Patients with oesophageal cancer who underwent oesophagectomy were identified from the Swedish Patient Registry, which has an excellent positive identification rate $(99.6 \%)$ for oesophageal cancer surgery. ${ }^{12}$ The Patient Registry also provided data pertaining to patient medical comorbidities. ${ }^{12}$ The comorbidities were classified according to the well-validated Charlson comorbidity index, and we did not count the oesophageal cancer diagnosis. ${ }^{13}$ The Swedish Causes of Death Registry provided accurate data for date and causes of death. This Registry has $100 \%$ coverage. If the diagnosis oesophageal cancer was listed as a cause of death, this mortality was defined as disease specific. The Swedish personal identity number, assigned to each Swedish resident at birth or immigration, was used to link individuals' data between registries and to identify their medical records. The clinical data collection was facilitated by a nationwide Swedish clinical network established in the mid-1990s. ${ }^{14}$ Medical records containing operation notes and histopathology reports of the cohort members were retrieved from all Swedish hospitals where oesophageal cancer surgery was performed during the study period. Data concerning neoadjuvant therapy, surgical therapy, names of the surgeons, pathological tumour stage and histological type were obtained from these individual patient records. The histopathological review has been demonstrated for its high accuracy. ${ }^{15}$ Neoadjuvant therapy was predominantly used in more recent years and when used was typically a combination of chemotherapy and radiotherapy. Tumour stage was classified according to the tumour nodal metastasis (TNM) classification of the Union Internationale Contre le Cancer (UICC).$^{16}$ Open transthoracic oesophageal resection with intrathoracic anastomosis was the dominating surgical procedure (95\%). The Regional Ethical Review Board in Stockholm, Sweden approved the study.

\section{Exposures, outcomes and covariates}

The exposures tested were a 7-week 'narrow holiday period' (25 June to 15 August) and a 14-week 'wide holiday period' (16 December to 7 January and 16 June to 31 August). The outcomes were all-cause 90-day and 5 -year mortality as well as disease-specific 5-year mortality. Covariates considered as potential confounding factors were age (continuous variable), pathological TNM stage (0, I, II, III or IV), Charlson Comorbidity Index $(0$, I or $\geq \mathrm{I})$, neoadjuvant therapy (yes or no), histological type (adenocarcinoma or squamous cell carcinoma) and cumulative surgeon volume of oesophagectomies during study period ( $\leq 6,7$ to 16 or 17 to 46 ).

\section{Statistical analysis}

Kaplan-Meier survival analysis was conducted to visualise crude long-term all-cause and disease-specific mortality. The holiday periods were analysed in relation to mortality using a multivariable Cox-proportional hazards model, providing HRs with 95\% CIs, adjusted for the seven potential confounding factors with categorisations as described above. These factors were included in the multivariable model because of their known prognostic influence. To manage missing data $(0.8 \%)$, a complete case analysis was carried out. The patients who underwent surgery during the narrow holiday period were compared with patients outside the narrow holiday period and with those outside the wide holiday period. Since the study period was long, we added a stratified analysis for an earlier calendar period (1987-1999) and a later calendar period (20002010). Follow-up ended at the date of death or end of study period, whichever occurred first. The statistical software SPSS V.22.0 (Statistical Package for the Social Sciences software, V.22, SPSS Chicago, Illinois, USA) was used for the data management and statistical analysis.

\section{RESULTS}

\section{Patients}

During the study period from 1987 to 2010, 1820 patients who underwent surgery for oesophageal cancer were included. Characteristics of these patients are presented in table 1 . The average age was 65.1 years, with the majority of patients (58.5\%) having a Charlson comorbidity index of 0 . The incidences of 90-day allcause, 5-year all-cause and 5-year disease-specific mortality were $11.4 \%, 74.7 \%$ and $79.7 \%$, respectively. In total, $206(11.3 \%)$ and $373(20.5 \%)$ patients were operated on during narrow and wide holiday periods, respectively. Comparison of patient demographics of operated on inside and outside of holiday periods, showed no major differences, except for an increased proportion of patients with Charlson comorbidity index $>1$ within the holiday periods (table 1 ).

\section{Narrow holiday period and mortality}

Kaplan-Meier survival analysis showed that oesophagectomy during the narrow holiday period did not affect allcause 90-day $(\mathrm{p}=0.84)$, all-cause 5-year $(\mathrm{p}=0.97)$ (figure 1) or disease-specific 5-year mortality $(\mathrm{p}=0.79)$. Regression analysis with adjustment for potential confounders further 
Table 1 Characteristics of study patients undergoing surgery for oesophageal cancer in Sweden in 1987-2010

\begin{tabular}{|c|c|c|c|c|c|}
\hline \multirow[b]{2}{*}{ Variable } & \multirow[b]{2}{*}{ Total number (\%) } & \multicolumn{2}{|c|}{$\begin{array}{l}\text { Narrow holiday period } \\
\text { number }(\%)\end{array}$} & \multicolumn{2}{|c|}{$\begin{array}{l}\text { Wide holiday periods } \\
\text { number }(\%)\end{array}$} \\
\hline & & No (\%) (n=1447) & Yes $(\%)(n=206)$ & No (\%) $(n=1447)$ & Yes $(\%)(n=373)$ \\
\hline Mean age (SD) & $65.1(9.6)$ & $65.1(9.7)$ & $64.9(9.0)$ & $65.1(9.7)$ & $65.2(9.1)$ \\
\hline \multicolumn{6}{|l|}{ Charlson comorbidity index } \\
\hline 0 & $1064(58.5)$ & $863(59.6)$ & $108(52.4)$ & $863(59.6)$ & 201 (53.9) \\
\hline 1 & 375 (20.6) & $301(20.8)$ & 45 (21.8) & $301(20.8)$ & $74(19.8)$ \\
\hline$>1$ & 381 (20.9) & $283(19.6)$ & $53(25.7)$ & $283(19.6)$ & $98(26.3)$ \\
\hline \multicolumn{6}{|l|}{ Tumour stage } \\
\hline $0-1$ & $422(23.4)$ & $339(23.6)$ & $52(25.4)$ & $339(23.6)$ & $83(22.3)$ \\
\hline II & $662(36.7)$ & $523(36.5)$ & $76(37.1)$ & $523(36.5)$ & $139(37.4)$ \\
\hline III-IV & $722(40.0)$ & $572(39.9)$ & 77 (37.6) & $572(39.9)$ & $150(40.3)$ \\
\hline \multicolumn{6}{|l|}{ Tumour histology } \\
\hline Adenocarcinoma & 792 (43.6) & 639 (44.3) & $83(40.5)$ & 639 (44.3) & $153(41.1)$ \\
\hline Squamous cell carcinoma & $1024(56.4)$ & $805(55.7)$ & $122(59.5)$ & $805(55.7)$ & 219 (58.9) \\
\hline \multicolumn{6}{|c|}{ Neoadjuvant therapy } \\
\hline No & $1231(67.7)$ & $986(68.2)$ & $131(63.6)$ & $986(68.2)$ & $245(65.7)$ \\
\hline Yes & 587 (32.3) & 459 (31.8) & $75(36.4)$ & 459 (31.8) & $128(34.3)$ \\
\hline \multicolumn{6}{|l|}{ Cumulative surgeon volume } \\
\hline$\leq 6$ & $1108(63.0)$ & $880(62.8)$ & $127(64.8)$ & $880(62.8)$ & $228(63.5)$ \\
\hline$\overline{7}-16$ & $569(32.3)$ & $455(32.5)$ & $60(30.6)$ & $455(32.5)$ & $114(31.8)$ \\
\hline $17-46$ & $83(4.7)$ & $66(4.7)$ & $9(4.6)$ & $66(4.7)$ & $17(4.7)$ \\
\hline \multicolumn{6}{|l|}{ Calendar period } \\
\hline $1987-1999$ & $992(54.5)$ & $790(54.6)$ & $112(54.4)$ & $790(54.6)$ & $202(54.2)$ \\
\hline $2000-2010$ & $828(45.5)$ & $657(45.4)$ & 94 (45.6) & $657(45.4)$ & $171(45.8)$ \\
\hline
\end{tabular}

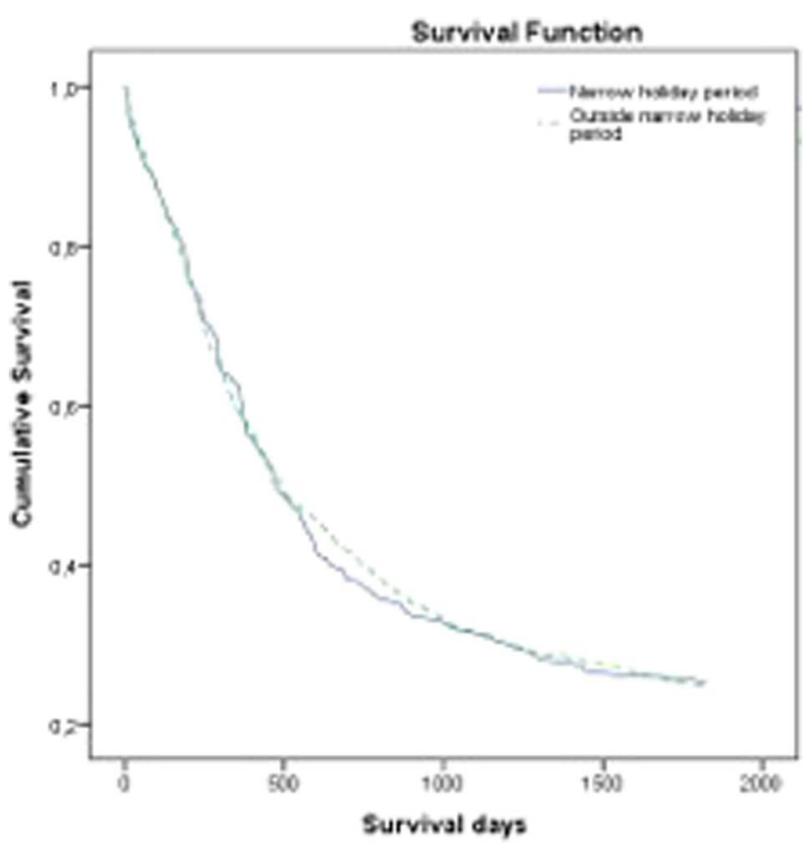

Figure 1 Kaplan-Meier survival curve for the effect of surgery of oesophageal cancer during a narrow holiday period (7 weeks) on all-cause 5-year survival.

showed that narrow holiday period did not increase the risk of all-cause 90 -day $(\mathrm{HR}=0.84,95 \%$ CI 0.53 to 1.33$)$, allcause 5 -year $(\mathrm{HR}=1.01,95 \%$ CI 0.85 to 1.21$)$ or diseasespecific 5-year mortality ( $\mathrm{HR}=1.04,95 \%$ CI 0.87 to 1.26 ) (table 2). Stratified analysis for earlier and later calendar periods showed no association between surgery during narrow holiday period and the risk of all-cause 90-day, allcause 5-year or disease-specific 5-year mortality (data not shown).

\section{Wide holiday period and mortality}

Kaplan-Meier survival analysis showed that oesophagectomy during wide holiday periods did not affect all-cause 90-day $(\mathrm{p}=0.43)$, all-cause 5-year $(\mathrm{p}=0.77)$ (figure 2$)$ or disease-specific 5-year mortality $(\mathrm{p}=0.90)$. Regression analysis with adjustment for relevant confounders further showed no increased risk of all-cause 90-day (HR=0.79, 95\% CI 0.55 to 1.13), all-cause 5-year $(\mathrm{HR}=0.96,95 \%$ CI 0.84 to 1.1$)$ or disease-specific 5-year mortality (HR=1.03, 95\% CI 0.89 to 1.19 ) (table 2$)$. The analysis stratified for calendar periods showed no association between surgery during wide holiday period and the risk of all-cause 90-day, all-cause 5-year and diseasespecific 5-year mortality (data not shown).

\section{DISCUSSION}

The results of this study disprove the hypothesis that oesophageal cancer surgery conducted during holiday periods increases the risk of short-term or long-term mortality.

The population-based design with virtually complete inclusion of all eligible patients in Sweden is a major 
Table 2 Oesophageal cancer surgery during narrow holiday period ( 7 weeks) and HRs with $95 \% \mathrm{Cls}$ of mortality

\begin{tabular}{|c|c|c|c|}
\hline Variable & $\begin{array}{l}\text { 90-day all-cause mortality } \\
\text { HR }(95 \% \mathrm{Cl})\end{array}$ & $\begin{array}{l}\text { 5-year all-cause mortality } \\
\text { HR }(95 \% \mathrm{Cl})\end{array}$ & $\begin{array}{l}\text { 5-year disease-specific mortality } \\
\text { HR }(95 \% \mathrm{Cl})\end{array}$ \\
\hline \multicolumn{4}{|c|}{ Narrow holiday period ${ }^{\star} \dagger$} \\
\hline No & 1 (reference) & 1 (reference) & 1 (reference) \\
\hline Yes & 0.84 (0.53 to 1.33$)$ & $1.01(0.85$ to 1.21$)$ & $1.04(0.87$ to 1.26$)$ \\
\hline \multicolumn{4}{|c|}{ Wide holiday period ${ }^{*} \ddagger$} \\
\hline No & 1 (reference) & 1 (reference) & 1 (reference) \\
\hline Yes & 0.79 (0.55 to 1.13$)$ & $0.96(0.84$ to 1.1$)$ & $1.03(0.89$ to 1.19$)$ \\
\hline
\end{tabular}

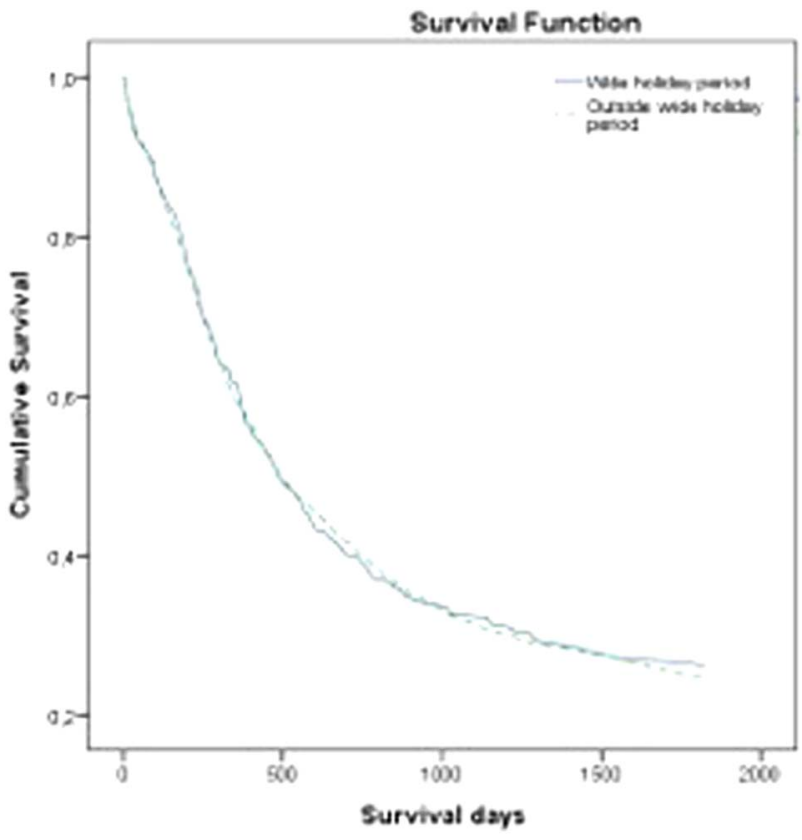

Figure 2 Kaplan-Meier survival curve for the effect of surgery for oesophageal cancer during a wide holiday period (14 weeks) on all-cause 5-year survival.

strength of the study. The large sample size, complete follow-up of all patients and the adjustment for all relevant confounding factors are other advantages. There are also limitations associated with retrospective observational studies such as this. However, the cohort used for this study has high accuracy in the correct identification of patients undergoing oesophagectomy for cancer, and the clinical data were collected from extensive review of medical records, which made it possible to have accurate and detailed information on exposures and covariates, not the least on key variables like date of surgery, surgeons' names and tumour stage. Finally, the Swedish system with personal identity numbers of all residents and a nationwide population registry for dates and causes of death enabled complete assessment of mortality, without loss to follow-up.

The present study shows that during narrow and wider holiday periods when staffing levels are potentially less experienced and somewhat depleted, there is no effect on postoperative short-term or long-term mortality. In view of the strong association between surgeon volume of oesophagectomies and mortality, ${ }^{4-6}$ these results reassuringly indicate that the experience of the surgeons is well maintained during holiday periods, at least in Sweden. This might be due to good planning of procedures to when the experienced surgeons are available during holiday periods and to well working referral systems of patients to other hospitals where the required expertise is available even during holiday periods.

To the best of our knowledge, this is the first study to examine the effect of cancer surgery during holiday periods on mortality. Thus, more research is needed and one should be cautious when considering any administrative or structural recommendations based on the findings of this single study. It would be of interest to consider an alternative population where the presence of surgical experience during the holiday period might be lower or in a centralised cancer service such as the UK, to further investigate this hypothesis. In a modern era with a low rate of perioperative mortality further studies may also include assessment of more subtle outcomes from oesophagectomy including complications, length of hospital stay and hospital transfer.

The negative results of the present study might be generalisable to other cancer surgical procedures. In the absence of any effect of surgery during holiday periods for oesophageal cancer on mortality, it seems unlikely that any such effect would exist for cancer procedures where the influence of surgeon volume is absent or weaker.

In conclusion, this large national study has demonstrated no worse mortality following major cancer surgery, in this study exemplified by oesophageal cancer surgery, during holiday periods. The benefit of ensuring a strategy for maintaining an adequate surgical experience even during holiday periods is recommended.

Contributors SRM contributed to the conception and design, collection and assembly of data, data analysis and interpretation, manuscript writing and final approval of manuscript. KW contributed to data analysis and interpretation, manuscript writing and final approval of manuscript. FM; data analysis and interpretation, manuscript writing and final approval of 
manuscript. PL; conception and design, collection and assembly of data, data analysis and interpretation, manuscript writing and final approval of manuscript. JL; conception and design, collection and assembly of data, data analysis and interpretation, manuscript writing and final approval of manuscript.

Funding The project was funded by the Swedish Research Council and the Swedish Cancer Society. SRM is supported by the National Institute of Health Research.

Disclaimer No support from any organisation for the submitted work; no financial relationships with any organisations that might have an interested in the submitted work in the previous three years, no other relationships or activities that could appear to have influenced the submitted work.

Competing interests None declared.

Provenance and peer review Not commissioned; externally peer reviewed.

Data sharing statement Statistical codes and the data set are available from the senior investigator JL (jesper.lagergren@ki.se) at the research group Upper Gastrointestinal Surgery, Department of Molecular medicine and Surgery, Karolinska Institutet, Stockholm Sweden, who will provide a permanent and citable home for the data set.

Open Access This is an Open Access article distributed in accordance with the Creative Commons Attribution Non Commercial (CC BY-NC 4.0) license, which permits others to distribute, remix, adapt, build upon this work noncommercially, and license their derivative works on different terms, provided the original work is properly cited and the use is non-commercial. See: http:// creativecommons.org/licenses/by-nc/4.0/

\section{REFERENCES}

1. Aylin P, Alexandrescu R, Jen MH, et al. Day of week of procedure and 30 day mortality for elective surgery: retrospective analysis of hospital episode statistics. BMJ 2013;346:f2424.

2. Zare MM, Itani KM, Schifftner TL, et al. Mortality after nonemergent major surgery performed on Friday versus Monday through Wednesday. Ann Surg 2007;246:866-74.
3. Markar SR, Karthikesalingam A, Thrumurthy S, et al. Volume-outcome relationship in surgery for esophageal malignancy: systematic review and meta-analysis 2000-2011. J Gastrointest Surg 2012;16:1055-63.

4. Finks JF, Osborne NH, Birkmeyer JD. Trends in hospital volume and operative mortality for high-risk surgery. $N$ Engl J Med 2011;364:2128-37.

5. Brusselaers N, Mattsson F, Lagergren J. Hospital and surgeon volume in relation to long-term survival after oesophagectomy: systematic review and meta-analysis. Gut 2014;63:1393-400.

6. Derogar M, Sadr-Azodi O, Johar A, et al. Hospital and surgeon volume in relation to survival after esophageal cancer surgery in a population-based study. J Clin Oncol 2013;311:551-7.

7. Almoudaris A, Mamidanna R, Bottle A, et al. Failure to rescue patients after reintervention in gastroesophageal cancer surgery in England. JAMA Surg 2013;148:272-6.

8. Lagergren J, Mattsson F, Lagergren P. Weekday of oesophageal cancer surgery and its relation to prognosis. Ann Surg 2016;263:1133-7.

9. van der Schaaf M, Johar A, Wijnhoven B, et al. Extent of lymph node removal during esophageal cancer surgery and survival. $J$ Nat Cancer Inst 2015;107:djv043.

10. Barlow L, Westergren K, Holmberg L, et al. The completeness of the Swedish cancer register: a sample survey for year 1998. Acta Oncol 2009;48:27-33.

11. Lindblad M, Ye W, Lindgren A, et al. Disparities in the classification of esophageal and cardia adenocarcinomas and their influence on reported incidence rates. Ann Surg 2006;243:479-85.

12. Ludvigsson JF, Andersson E, Ekbom A, et al. External review and validation of the Swedish national inpatient register. BMC Public Health 2011;11:450.

13. Charlson ME, Pompei P, Ales KL, et al. A new method of classifying prognostic comorbidity in longitudinal studies: development and validation. J Chronic Dis 1987:40:373-83.

14. Lagergren J, Bergstrom R, Lindgren A, et al. Symptomatic gastroesophageal reflux as a risk factor for esophageal adenocarcinoma. N Engl J Med 1999;340:825-31.

15. Rouvelas I, Zeng W, Lindblad M, et al. Survival after surgery for oesophageal cancer: a population-based study. Lancet Oncol 2005;6:864-70.

16. Sobin LH, Gospodarowicz MK, Wittekind C. UICC TNM classification of malignant tumors. 7th edn. Wiley Blackwell, 2009. 